7.

Derecho económico 



\title{
LA NOCIÓN DE DERECHO ECONÓMICO
}

[The Notion of Economic Law]

\author{
Enrique AimOne GiBSON* \\ Pontificia Universidad Católica de Valparaíso, Chile \\ Adolfo Silva Walbaum** \\ Pontificia Universidad Católica de Valparaíso, Chile
}

\begin{abstract}
RESUMEN
El trabajo trata de precisar cuáles son el concepto y el contenido de la disciplina del derecho económico. Para el desarrollo del referido cometido, se parte por describir el alcance de los conceptos de "orden público económico" y "constitución económica”, en tanto base de la doble influencia que tanto la escuela francesa como la germana influyeron en
\end{abstract}

\begin{abstract}
This work aims at specifying which the concept and the content are of the discipline of economic law. To do this, this article first describes the scope of the concepts of "economic public order" and "constitutional economics" as the basis of the double influence that both the French and German schools had in the origin and development of the so-called
\end{abstract}

RECiBIDO el 20 de noviembre de 2014 y ACEPTADO el 12 de marzo de 2015

* Profesor emérito de la Pontificia Universidad Católica de Valparaíso. Correo electrónico: dirder@ucv.cl.

** Doctor en Derecho por la Universidad de Granada; magíster en Derecho por la Pontificia Universidad Católica de Chile; profesor de derecho económico y comercial en la Pontificia Universidad Católica de Valparaíso. Correo electrónico: adolfo. silva@ucv.cl. Los autores agradecen los comentarios a este trabajo del profesor José Luis Guerrero Becar de la Facultad de Derecho de la Pontificia Universidad Católica de Valparaíso. 
el origen y desarrollo del denominado derecho económico. Paralelamente, se ofrece una síntesis de las principales doctrinas que la dogmática jurídicoeconómica ha planteado en la búsqueda de una respuesta al pasado, presente, y futuro de esa rama.

\section{Palabras clave}

Derecho económico - Orden público económico - Constitución económica. economic law. At the same time, an overview of the main doctrines proposed by the legal-economic doctrine in the search for an answer to the past, present and future of this discipline is provided.

\section{KEYWORDS}

Economic law - Economic public order - Constitutional economics.

\section{INTRODUCCIÓN}

En 1961, Cottely, reflexionando sobre el concepto de derecho económico, afirmó: "es más fácil crear un nuevo concepto que delimitar su contenido" ${ }^{1}$. En dicha línea de ideas, y para efectos de poder delimitar el contenido e intentar un concepto de derecho económico, previamente es necesario comprender el contexto que le da origen, con una vinculación ineludible a la ciencia económica, la cual está en constante evolución en especial por los cambios ideológicos que la inspiran.

Tal vez, por la misma razón, intentar una determinación del continente como algo previo al contenido o, en otras palabras, la delimitación del concepto antes que de la materia, atrajo adeptos fervorosos hace más de cincuenta años, pero también opositores decididos a pensar en una rama autónoma del derecho que se hiciera cargo de la vinculación entre derecho y economía.

En Chile, hasta las décadas de los sesenta y setenta del siglo XX, no existía aún la plena convicción de que el estudio de esa vinculación pudiera conformar una rama independiente del derecho: había una falta de claridad conceptual que se hacía cada vez más latente. Al respecto, Santa María, en el año 1977, señalaba: "A pesar que en las Escuelas de derecho chilenas existen Departamentos de derecho económico y las cátedras respectivas, desde hace aproximadamente siete años, no se ha producido entre los especialistas un consenso conceptual del ramo, ni consecuencialmente [sic] una identificación de contenidos que permita uniformar en alguna medida los programas respectivos" .

${ }^{1}$ Cottely, Esteban, Derecho económico, en Trimestre Económico, 28 (México, Fondo Cultura Económica, 1961) 109, p. 25.

${ }^{2}$ Santa María, Raúl, Derecho económico: reflexiones sobre concepto y contenido, en Revista Chilena de Derecho, 4 (1977), p. 295. 
Transcurridos ya algunas décadas de opiniones en la doctrina nacional sobre lo que debe entenderse por derecho económico, creemos que el actual estado de la cuestión entrega una oportunidad para proponer una noción de derecho económico ${ }^{3}$, que dé cuenta de su sentido y alcance, manifestaciones y limitaciones.

\section{EL DERECHO ECONÓMICO COMO RAMA DE LA CIENCIA JURÍDICA}

\section{Su origen. El positivismo jurídico.}

El origen de lo que actualmente entendemos por derecho económico se encuentra en el desarrollo del denominado positivismo jurídico, en cuanto corriente del pensamiento centrada en la naturaleza del derecho que la hace consistir exclusivamente en la norma obligatoria vigente, a diferencia de la denominada dogmática jurídica, la cual apunta a los principios rectores de la dictación y aplicación de la norma, más que a lo que rezase de manera exclusiva la regla escrita.

En efecto, fue a partir del positivismo jurídico que se asentaron pilares fundamentales de lo que en la actualidad constituye una parte importante del denominado derecho económico. Dentro de dichos pilares, se adoptó, como medio de organización para la aplicación y la enseñanza del derecho, el concepto de rama ${ }^{4}$. Para ello, se entendió por rama a un conjunto de normas íntimamente vinculadas entre sí. La rama pasaba a ser una parte, y siguiendo la metáfora, todo el árbol era el derecho.

Así las cosas, las ramas del derecho tomaron sus nombres según su contenido, y constituyendo en su conjunto un árbol, a veces bastante frondoso, como en el caso entre otros, del derecho civil, el derecho penal, el derecho comercial o el derecho procesal 5 . Todos estos derechos o ramas tuvieron su base en una norma de rango superior fundante, que es la constitución.

${ }^{3}$ En la misma línea de ideas, pero refiriéndose en particular al caso chileno, YRARRÁZAVAl Covarrubias, Arturo, Orden público económico: ficción o realidad; en Revista del Abogado, 15 (1999), disponible en internet http://www.colegioabogados.cl [fecha de visita: 1 de octubre de 2014], señala: "Difícil habría sido plantearse el tema del contenido fundamental del derecho económico hace algunas décadas. Prueba de ello fue la inexistencia del ramo dentro de los estudios de derecho. Sin embargo, hoy en día se puede constatar en Chile y en todos los regímenes jurídicos desarrollados, un contenido bastante claro y específico".

${ }^{4}$ Sobre el concepto de rama del derecho, véase: Bascuñán Valdés, Aníbal, Introducción al estudio de las ciencias jurídicas y sociales ( $2^{\text {a }}$ edición, Editorial Jurídica de Chile, 1960), pp. 228-230.

${ }^{5}$ Tales normas dictaban reglas y constituían derechos subjetivos. Y para su aplicación precisaban, sobre todo los derechos civiles y penales, derechos o normas que regulaban su aplicación, que se pasaron a llamar genuinamente procedimiento. 
Surge, en consecuencia, todo un conjunto de ramas del derecho con fundamentos en la propia constitución.

\section{La codificación y su superación por la legislación especial.}

El ejemplo de los Estados Unidos de Norteamérica de dotarse de una constitución, es decir, de contar con una normativa ordenada, sistemática, lógica, libre de vacíos y de contradicciones, fue seguido por muchos Estados. Napoleón Bonaparte, desde 1800 impulsó la tarea de organizar el derecho francés y, comenzando por el civil, dispuso al efecto, que todo el derecho de la propiedad privada, el matrimonio, la filiación y la sucesión, fuesen regulados por un único código, es decir, por una sola ley que fuera comprensiva de todas esas normativas, y autosuficiente para determinar su sentido.

Consecuencia de este desarrollo fue el hecho que el derecho privado francés se estructuró precisamente en una sola norma o ley, reflejado por tanto, en un solo código, que tomó como era de esperarse, el nombre de Napoleón, en tanto ilustre propulsor de esta iniciativa. Empezaba así en el mundo latino el período denominado de la codificación ${ }^{6}$.

A partir de entonces, en varios países del mundo se repitió el fenómeno descrito. Se comenzó a señalar lo que los comparatistas ${ }^{7}$ denominan el derecho europeo-con tinental, y cada rama del derecho, se comenzó a estructurar en base a un conjunto de normas reunidas en un código, como casi único material de estudio para abogados y jueces.

La expresión "código" sirvió para referirse a la rama, a la ley, y además, esta ley fue el propio tratado para explicarlo a estudiantes. El libro que

\footnotetext{
${ }^{6}$ Sobre el fenómeno de la codificación, véase: GuZmán Brito, Alejandro, Para la historia de la fijación del derecho civil en Chile durante la República, VIII: Crítica al derecho vigente como presupuesto de la codificación en torno al primer tercio del siglo XIX, en Revista de Estudios Histórico-Jurídicos, 5 (Valparaíso, 1980), pp. 267 ss.; GUZMÁN Brito, Alejandro, Andrés Bello codificador. Historia de la fijación y codificación del derecho civil en Chile (Santiago, Ediciones de la Universidad de Chile, 1982), I, pp. 119 ss.; GuZmán Brito, Alejandro, La codificación civil en Iberoamérica. Siglos XIX y XX (Santiago, Editorial Jurídica de Chile, 2000), pp. 189 ss.; GuZMÁn Brito, Alejandro, La influencia del Código Civil Francés en las codificaciones americanas, en Cuadernos de Análisis Jurídicos: De la codificación a la descodificación (Santiago, Ediciones Universidad Diego Portales, 2005), II, pp. 27-60.

${ }^{7}$ Lit.: Cabrillac, Rémy, Las codificaciones (traducción de Paulina Pulido Velasco y Claudia Bulnes Olivares, Santiago, Flandes Indiano, 2009); Turner SaElzer, Susan, Reseñas a Remy Cabrillac, "Las codificaciones", en Revista de Derecho de la Universidad Austral, 22 (Valdivia, 2009) 1. pp. 293-294; Glendon, Mary Ann Gordon, Michael - Carozza, Paolo, Comparative Legal Traditions (2a edición, St. Paul, Minn., West Group, 1999).
} 
explicaba el código era el propio código, que servía como forma de enseñar la ley. Dicha tendencia, y la aplicación ampliada al resto del derecho, concitó igual desarrollo. Fue así como los ámbitos penales y comerciales repitieron el mismo proceder ${ }^{8}$.

La forma en que se organizó la enseñanza de la ciencia jurídica9 en esta época, consistió en denominar a cada cátedra bajo los nombres de sus respectivos códigos ${ }^{10}$. Fue así como para el estudio de una rama del derecho se estudiaba el código respectivo, surgiendo la denominación de asignatura jurídica, en tanto rama del derecho que estando radicada en una ley única o código, es también objeto de estudio y enseñanza a nivel de educación superior.

En materias más vinculadas a la regulación jurídica de lo económico, cuando la explotación de los recursos económicos se expandió, este sistema basado en ramas del derecho, que consideraba como sinónimos a los conceptos de ley y código, comenzó a resultar insuficiente.

En efecto, desde la segunda mitad del siglo diecinueve, y especialmente con el fenómeno de la revolución industrial, países sujetos al régimen de codificación, comenzaron a explotar con cada vez con mayor más intensidad sus distintos recursos económicos en áreas tales como minería, pesca o agricultura. Lo anterior, requirió la dictación de leyes especiales para cada área o sector, lo cual hizo que el modelo de codificación que hemos descrito, en tanto regulación de estos sectores económicos, fuese incapaz de sostener semejante acervo normativo ${ }^{11}$.

De esta forma, las nuevas instituciones jurídicas no tenían cabida ya en el sistema de códigos, y requirieron de leyes especiales. Algunas materias

${ }^{8}$ En cambio, tratándose del caso primero de Gran Bretaña y luego del Reino Unido, se siguió otra senda muy diferente. No se dieron leyes, sino que establecieron jueces. Éstos juzgaban, y sus sucesores durante siglos, habían de estar a lo decidido por ellos. Prevaleció el "case law" o derecho del caso. Los españoles exportaron el derecho europeo-continental a Sudamérica; los ingleses por su parte, llevaron a América del Norte su "common law", con la técnica del stare decisiis.

${ }^{9}$ Sobre esta materia véase: GuZMÁn Brito, Alejandro, La influencia del Código Civil francés en las codificaciones americanas, cit. (n. 6), pp. 27-60.

${ }^{10}$ Así, por ejemplo, la asignatura de derecho penal se centraba en el estudio del Código Penal, la de derecho Comercial, en el Código de Comercio, etc.

${ }^{11}$ En el ámbito de los recursos minerales, del agro, aguas, transporte, instituciones nuevas del derecho comercial-banca, moneda, derivados, nuevas formas de agrupación societaria-. En esta época, se generaron -o expandieron- el comercio, la navegación, la explotación de las minas, de las aguas, la regulación de la enseñanza, la promoción de la salud, etcétera, y con ello nacieron las ramas del derecho. Se dictaron las leyes de aeronavegación, de Bancos, de servicios eléctricos, de gas, de alcantarillado, pero no se llegaron a formular nuevos Códigos salvo casos aislados, como el de minería, aguas y tributario. 
tomaron formas tan complejas que, aun teniendo cabida en el sistema codificado, hubieron de abandonarlo y salirse de su código para formar su propia normativa ${ }^{12}$. Bajo este escenario, la normativa básica se estableció en leyes generales no comprensivas de toda la materia.

Se termina de esta forma, el proceso de codificación como técnica general de legislación, dando paso al binomio código-ley, imperante hasta nuestros días.

\section{El derecho económico y su relación con otras ramas del derecho.}

Efectuada una revisión general de las técnicas legislativas utilizadas por el derecho económico, corresponde ahora abocarnos al análisis de la relación existente con otras ramas del derecho ${ }^{13}$.

a) El derecho económico y el derecho comercial. La primera relación que estudiaremos es aquella que conecta al derecho económico con el denominado derecho comercial. Al respecto, cabe considerar que dicha relación se aprecia precisamente a nivel de alcances conceptuales de ambas disciplinas, y no por tanto, en todo aquello que dice relación con las materias que puedan ser consideradas como parte de una u otra especialidad.

De hecho, a nivel de contenido, lo que para una realidad legislativa puede ser considerado como parte del derecho comercial, para otros en cambio, perfectamente podría ser considerado como parte del derecho económico.

Luego, de lo que se trata es si el derecho económico en tanto rama

${ }^{12}$ En Chile tal acaeció con la banca y la moneda respecto del Código de Comercio; o el matrimonio y el arrendamiento con relación al Código Civil, y los delitos tributarios y otros de alta complejidad que no están en el Código Penal.

${ }^{13}$ Para Cottely "La base de la división del material jurídico de la que el derecho económico constituye una rama, es la de las valoraciones que tienen como objetivo la norma. La gran división, en este criterio, es la de distinguir entre el derecho con base ideológica no económica y con base ideológica económica. Según él, toda norma jurídica puede ser valorable desde el punto de vista de la economía o de la vida económica de la respectiva sociedad. Este criterio ya nos da un conjunto de normas -o dicho de otra manera-, descarta normas del análisis. Sin embargo, no es éste criterio final y definitivo. En todo este conjunto normativo económicamente valorable, hay normas que admiten esta valoración, pero que no la exigen necesariamente. También estas normas son descartadas del análisis. Esta doble operación de descarte nos conduce a precisar el concepto y contenido del derecho económico. Este no es otro que el conjunto de normas que, en su proceso de aplicación, estudio o valoración, exigen necesariamente una valoración económica”. Véase: Cottely, Esteban, Derecho económico, cit. (n. 1), p. 44. 
de la ciencia jurídica, es o no diferente y por tanto autónoma, de lo que podamos entender como derecho comercial.

Esta discusión no es nueva, y tampoco se encuentra cerca de agotarse. Sin ir más lejos, en el trabajo del año 1964 de uno de los autores de este artículo $^{14}$ ya nos fue posible efectuar una referencia a este tema, entre los llamados formalistas objetivos citados por Cottely ${ }^{15}$.

b) El derecho económico y el derecho administrativo. En segundo término, encontramos la relación existente entre el derecho económico y el derecho público, y más específicamente, entre el derecho económico y el denominado derecho administrativo.

Sin perjuicio del análisis que haremos más adelante en torno al origen público de la cátedra de derecho económico ${ }^{16}$-en tanto sucesor natural de la otrora asignatura denominada "política económica"-por ahora, nos limitaremos a señalar y reconocer la necesaria independencia que entendemos presenta el derecho económico respecto del denominado derecho administrativo.

En efecto, y tal como uno de los autores de este artículo viene sosteniendo desde hace cinco décadas: "No se divisa razón alguna que nos requiera permanecer en el campo del derecho administrativo y crear una especie de derecho administrativo del sector económico. Tal planteamiento podría eventualmente ser una necesidad del ramo de derecho administrativo, pero no de la urgencia evidente de buscar las categorías de una rama del derecho que comprenda todas las normas -de la naturaleza que sean- que regulen la macroeconomía de una determinada nación" ${ }^{17}$.

c) El derecho penal económico. Finalmente, quisiéramos efectuar una breve reflexión acerca de la relación existente entre la ciencia penal y el aspecto económico, o en otras palabras, acerca del denominado derecho penal económico.

Sobre este asunto, traemos a colación la opinión de Tiedemann ${ }^{18}$, para quien el derecho penal económico no sería otra cosa que la arista económica de la ciencia jurídica penal, o en palabras del propio autor: "De lo dicho se extrae, para resumir, en primer término un concepto limitado de derecho

${ }^{14}$ Aimone Gibson, Enrique, Concepto y contenido del derecho público económico, en Revista de Derecho y Ciencias Sociales, 128 (Facultad de Ciencias Jurídicas y Sociales y Colegio de Abogados de Concepción, 1964), pp. 138-169.

${ }^{15}$ Cottely, Esteban, Derecho económico, cit. (n. 1), p. 28.

${ }^{16}$ Véase infra p. 15.

${ }^{17}$ Aimone Gibson, Enrique; Concepto y contenido del derecho público económico, cit. (n. 14), p. 140.

${ }^{18}$ Tiedemann, Klaus, El concepto de derecho económico, de derecho penal económico $y$ de delito económico, en Revista Chilena de Derecho, 10 (1983), p. 67. 
económico y de derecho penal económico. Tal concepto abarca aquellas partes del derecho Penal que tutelan primordialmente el bien constituido por el orden económico estatal en su conjunto, y en consecuencia, el flujo de la economía en su organicidad, en una palabra, la economía nacional. En tanto este organismo económico se halla, como valor supraindividual, preponderantemente institucionalizado y ordenado, dirigido y vigilado por vía de las medidas administrativas - con lo cual se verifica la política económica-, la materia alcanzada por la definición es el derecho penal económico administrativo" ${ }^{19}$.

\section{El APORTE DE LAS NOCIONES DE ORDEN PÚBLICO ECONÓMICO Y CONSTITUCIÓN ECONÓMICA PARA LA CONSTRUCCIÓN DEL DERECHO ECONÓMICO}

Cabe reconocer que toda división o clasificación en derecho tiene por objeto analizar, para luego entender. Comprendido aquello, es posible realizar el proceso inverso, es decir, de la división avanzar a la integración. Es precisamente en la integración donde el problema persiste, ya que una rama del derecho que sea capaz de comprender toda la presencia de la economía en el derecho, resulta impracticable y, además, inútil.

Efectivamente no solamente el comercio, sino que también el matrimonio, la sucesión hereditaria o la estafa, tienen un elemento económico, pero al mismo tiempo, integran respectivamente, ramas tan distintas como lo pueden ser el derecho civil o el derecho penal.

Por tal motivo, se requiere de la búsqueda de algún otro elemento básico que haga necesaria y justifique una rama especializada de estudio del derecho y la economía.

Una aproximación a un elemento aglutinador lo entregan las nociones de orden público económico y de constitución económica, provenientes de vertientes distintas, el orden público económico ("ordre public économique"), de nociones privatistas del derecho francés, y la noción de constitución económica ("Wirtschafsverfassung") del derecho alemán.

\section{El orden público económico.}

Fue la escuela francesa quien acuñó el término "ordre public économique". El concepto de "orden" ${ }^{20}$, en la citada escuela ${ }^{21}$, fue desarrollada

${ }^{19}$ Ibíd., p. 67

${ }^{20}$ Este término y el concepto que designa, significa según lo enseña SAN AGUSTín, la recta disposición de las cosas para efecto de alcanzar un objetivo determinado. Véase: San Agustín, Obras de San Agustín en edición bilingüe (Madrid, Biblioteca de Autores Cristianos, 1969). pp. 589-691.

${ }^{21}$ El término decisivo de dicho concepto es el de "ord re", “orden” en castellano, 
especialmente por Gérard Farjat, en su obra L'ordre public économique ${ }^{22}$.

La obra de Farjat, está precedida de un lúcido prólogo a cargo de Berthold Goldman ${ }^{23}$, quien adelanta algunas ideas, no solo respecto del concepto objeto de estudio, sino también, acerca del marco histórico en que se desarrolló. La primera idea que entrega Goldman es que la libertad contractual pertenece al pasado, no existiendo la autonomía de la voluntad ni tampoco la supremacía del contrato.

Surge de esta forma, el concepto de orden público, en tanto concepto clave de la referida limitación de libertad, y en donde el Estado se instala entre las partes contratantes. Su actividad toma la forma de ley, de gobierno y de juez.

En otras palabras, Goldman invita a dejar de lado la idea de que el contrato surge por deliberación de dos sujetos con intereses contrapuestos, que quieren armonizarlos por un clausulado que ellos, frente a frente, negocian calmadamente, y compartiendo un mismo plano de poder y de autonomía. Ese mundo ya no existe.

En el plano económico, la libertad queda sustituida por reglas relativas a la organización económica general; por el establecimiento autoritario de relaciones sociales, y por la propia economía interna del contrato ${ }^{24}$.

En definitiva, esta intervención estatal se manifestará según Farjat, de dos maneras bien precisas.

La primera de ellas a través del ejercicio, directamente por parte el Estado, de alguna actividad económica. Una segunda forma de intervención, se ve reflejada a través de la insinuación -no sin cierta coerción- por parte del Estado al empresario, para que desarrolle una actividad económica conforme a las ideas de aquél.

Sin abandonar todavía la doctrina francesa, Vasseur -citado por Farjatexpresa que el orden público económico da lugar a un derecho económico, que comprende la regulación de actividades directas del Estado en el plano económico, medidas por las cuales el Estado sugiere y estimula una determinada actividad económica, y finalmente los procesos propios del denominado orden público económico.

de antigua raigambre escolástica, (recta dispositio rerum: "adecuada disposición de las cosas"). En el caso, las cosas eran normas e instituciones públicas, para lograr ese objetivo que es el "ordre", y el objetivo final de la satisfacción de necesidades a nivel nacional.

${ }^{22}$ FARJAT, Gerard, L'ordre public économique (Paris, Librairie Général de Législation et Jurisprudence, 1963). pp. 77 ss.

${ }^{23}$ Ibíd., pp. 5-7.

${ }^{24}$ Sobre esta materia: Fermandois VöHringer, Arturo, Ripert y su influencia en el concepto de orden público económico: auge y caída de una visión dirigista, en Revista Chilena de Derecho, 32 (2005), pp. 7-18. 
En lo que guarda relación con su concreción, el primero en ser reconocido se refiere al denominado orden público monetario. Recordemos que el dinero si bien mide la riqueza, al mismo tiempo como medio de pago, es una creación estatal. De ahí que fuese Georges Ripert el primero en hablar de orden público económico, y para ello sostuvo que éste se refiere a la producción, al reparto y al consumo, a través de la moneda en sus diferentes formas ${ }^{25}$.

Finalmente, para otros como Carbonnier ${ }^{26}$-citado por Goldman- es posible distinguir dos tipos de orden público económico: uno que es de dirección y operación económicas, y otro en cambio, que es de protección de diversas formas contractuales, que tienden a proteger a la parte más débil en la relación jurídica en que se está formando a saber: trabajadores de predios agrícolas, usuarios de bienes vendidos en el comercio, deudores en las relaciones viciadas del contrato, y consumidores.

\section{La constitución económica ${ }^{27}$.}

También la sociedad alemana se dio, como en el caso de Francia, un orden, al cual se denominó "Verfassung" ("Constitución”).

A diferencia del caso francés, el orden alemán no era puramente jurídico, sino que contenía además valores.

Estos valores se referían a la persona humana y a su dignidad. En concreto, a través de dichos valores, los alemanes rechazaron de plano elementos socialista-marxistas como lucha de clases y dictadura del proletariado. No era necesariamente neoliberal ${ }^{28}$, pero sí fue decisivamente antimarxista.

\footnotetext{
${ }^{25}$ No obstante las diferencias que podemos encontrar entre el pensamiento de Georges Ripert y Gerard Farjat, ambos eminentes juristas concuerdan en lo siguiente: i) Orden público es un concepto variable en el tiempo y en el espacio; ii) En el derecho privado, corresponde a la ley determinar cuáles instituciones y conceptos son de orden público; iii) En cuanto al derecho público, todas sus normas por definición, son de orden público; iv) El concepto de orden público no puede quedar indeterminado legalmente pues constituiría un grave peligro para el Estado de Derecho. Cfr. FARJAT, Gerard, L'ordre public économique, cit. (n. 22), pp.77 ss.; y RIPERT, Georges, Le régime démocratique et le droit civil moderne (Paris, Librairie Général de Législation et Jurisprudence, 1936).

${ }^{26}$ Sobre esta materia: CARBonnier, Jean, Droit Civil, IV: Les obligations (Paris, Presses Universitaires de France, 1956).

${ }^{27}$ En el caso chileno, entenderemos por constitución económica al "conjunto de normas de rango constitucional que regulan los actores y los límites dentro de los cuales debe desenvolverse la actividad económica de un país". Véase: Guerrero BECAR, José Luis, Regulación constitucional del orden económico. La experiencia chilena: Constitución Política de la República de 1980 (memoria de licenciatura, Universidad Católica de Valparaíso, 1991), p. 108.

${ }^{28}$ Para un análisis detallado de la relación existente entre libertad y constitución
} 
A partir de este "Verfassung", los alemanes crearon su "Wirtschaftsrecht", es decir, su derecho de la economía, o derecho de guerra para otros ${ }^{29}$.

Pero luego este derecho se pacificó cuando pasa a conformar lo que en la actualidad conocemos como constitución económica ("Wirtschaftsverfassung").

De esta forma, mientras Francia insistió en su "ordre public économique", Alemania por su parte, destrozada hacia el año 1945, rehizo su presencia en el concierto de las naciones, estableciendo su "constitución económica" e impulsando el modelo de economía de mercado ${ }^{30} \mathrm{o}$ social de mercado ${ }^{31}$.

En esta economía social de mercado, se reconocieron el valor de la persona humana, la importancia de la libertad de emprendimiento, y el carácter subsidiario del Estado ${ }^{32}$.

\section{PRINCIPALES DOCTRINAS PARA UNA NOCIÓN DE DERECHO ECONÓMICO. PRECURSORES, FUNDADORES Y MODERNOS}

Probablemente una de las más importantes aristas acerca de la noción de derecho económico se refiere al aporte que sobre el particular han efectuado la doctrina de los autores de la dogmática jurídica.

A propósito de dicho aporte, y al cumplirse casi cuarenta años de lo que en su oportunidad ${ }^{33}$ uno de los autores de este artículo presentó como

económica, recomendamos Guerrero BeCAR, José Luis, La libertad para desarrollar actividades económicas del Art. $19 N^{o} 21$ y la constitución económica, en Persona y Sociedad, 3 (Santiago, Instituto Latinoamericano de Ciencias Sociales - Universidad Alberto Hurtado, 2000) 6, pp. 141-156.

${ }^{29}$ En efecto, corría el año 1910 y los alemanes estaban aún en una época que los enfrentaba a los franceses en Lorena, Alsacia y el Sarre, ante lo cual el derecho determinaba instrumentos para el uso de elementos bélicos.

${ }^{30}$ Cabe precisar que el término economía de mercado si bien fue creado en el año 1933 (con la obra del abogado Franz Böhm), alcanzó su real desarrollo hacia la década de los cincuenta del siglo XX.

${ }^{31}$ Empezó llamándose economía de mercado, pero un ilustre miembro de la Compañía de Jesús llamado Oswald von Nell-Breuning, S. J, pidió agregar al nombre el adjetivo social, con el fin, obviamente, de despojar a esta naciente economía de mercado de la sombra de cierta brutalidad que muchas veces la ha acompañado.

${ }^{32}$ De esta forma, el Estado pasa a ser solo un auxiliar para la convivencia social. Es consumidor, regulador, y sancionador en materia económica, es decir, de riqueza, pero no obstante lo anterior no se transforma en dueño de los recursos económicos ni rector de su uso, al asumir un rol subsidiario, de segundo plano, competente solo para lo que otras entidades no pueden hacer, o no pueden hacer sin su ayuda.

${ }^{33}$ Aimone Gibson, Enrique, Para un concepto de derecho económico, en Revista de Derecho de la Universidad de Concepción, 164 (1976), p. 26. 
una suerte de compendio de las principales corrientes del pensamiento existente hasta esa fecha sobre esta materia, ahora, en los inicios del siglo XXI, quisiéramos aprovechar la ocasión, para presentar una propuesta más actualizada e inclusiva.

\section{El preámbulo y criterio de clasificación.}

Antes que todo, estimamos necesario replicar y reforzar algunos de los comentarios que uno de los autores de este trabajo realizó en el año 1976, en tanto pensamos que éste fue, y seguirá siendo la mejor senda para responder a la noción de derecho económico.

En la oportunidad, y precisamente bajo el epígrafe de preámbulo ${ }^{34}$ se sostuvo que: "Sea nuestra primera preocupación la de definir el concepto que sirve de base al sistema legal que intentamos con esta obra. No es el concepto de derecho económico de los tradicionales en la dogmática jurídica. Sólo aparece, muy espaciadamente, en obras de los albores del siglo XIX, y ya en el siglo XX adquiere, desde los primeros años de la centuria, cada vez más importancia”.

En otras palabras, el referido preámbulo, corresponde el estado previo de la cuestión que tratamos de dilucidar, al tratar de aclarar en qué consiste aquella rama del derecho que denominamos como derecho económico.

En síntesis, estimamos que la idea de que el continente se encuentra en un estado anterior y previo al contenido, sirvió hace cuatro décadas para ilustrar las principales doctrinas del pensamiento, y nos sigue iluminando ahora, al pretender alcanzar su alcance conceptual aplicable a los tiempos que corren.

Respecto al criterio que utilizaremos para efectuar la distinción entre los autores, cabe señalar que éste, al igual que antes, se cimienta en un orden cronológico, pero con especial énfasis de la influencia de lo económico en lo jurídico, o en otras palabras, de la ciencia económica hacia la ciencia jurídica.

Para estos efectos, reconoceremos tres grupos de pensadores. Los precursores $^{35}$, los fundadores ${ }^{36}$ y finalmente agregaremos los modernos ${ }^{37}$,

${ }^{34}$ Ibíd., p. 25.

35 "Un grupo lo forman, indudablemente, los precursores. En ellos existen las tendencias más heterogéneas, pero caben grupos, formados, sea en torno a la profesión cameralista de sus autores, a la adhesión al ius naturalismo, o a la concepción de un "derecho de guerra", nacido bajo fuerte motivación de la estructuración de la organización económica interna para la Primera Guerra Mundial”. Véase: Aimone Gibson, Enrique, Para un concepto de derecho económico, cit. (n. 34), p. 26.

${ }^{36}$ Ibíd.

${ }^{37}$ Para entender lo que está a la base de los modernos, recordemos que "Sigue la 
aunque haya otros ${ }^{38}$.

\section{Los precursores. Piepenbrock y el pensamiento de los siglos XVIII y XIX.}

Este primer grupo de pensadores lo ubicamos en la concepción de un derecho económico anterior al siglo XIX.

En particular, en el pensamiento de Rudolf Piepenbrock, quien efectuando "Un esfuerzo laudable, viendo los orígenes del pensamiento de la Agnóstica en sentido retroactivo, incluso hasta el siglo XVIII", nos presenta un "Esquema, meramente, con una serie de juristas que contribuyeron a precisar el concepto"39.

De esta forma, Piepenbrock ve, por ejemplo, en escritos del año 1747, en que un anónimo cameralista trata, en forma conjunta, asuntos jurídicos, económicos y de administración policial, lo que podríamos considerar como los primeros acercamientos en torno a lo que hoy denominamos como derecho económico ${ }^{40}$.

La pesquisa de Piepenbrock continúa también, en los escritos de los iusnaturalistas alemanes del siglo XVIII. Entre ellos destaca Johannes Adam L. B. von Ickstatt (1702-1776), a quien indica como un propulsor de las ideas de la Ilustración, sobre todo, en materias de jurisprudencia y educación, y a Joachim Georg Daries (1714-1791) destacado, además de jurista, como matemático y filósofo ${ }^{41}$.

tendencia que caracteriza de económica un sector del derecho según el contenido de sus normas, marcadamente destinados a servir de pautas de las actividades económicas. Destacamos a continuación la posición, quizás única, de Hedemann, que usa el término, no para denominar determinado sector del derecho, sino el derecho íntegro de un determinado tiempo (el nuestro), caracterizado, según él, por la presencia de los fenómenos, espíritu y motivaciones de la economía en la estructuración y aplicación del derecho": Aimone GibSON, Enrique, Para un concepto de derecho económico, cit. (n. 34), p. 26.

38 "Otros grupo de autores se afirma en una finalidad, generalmente, metajurídica, de la norma, para asignarla o no al sector que denominan derecho económico. Esta finalidad puede ser "crear el orden económico", "contribuir al desarrollo económico más acelerado”, etc. Finalmente tenemos la posición, también solitaria, de Esteban Cottely, que recurre a inquirir la valoración de la norma para los efectos de su clasificación": Aimone Gibson, Enrique, Para un concepto de derecho económico, cit. (n. 34), p. 26.

${ }^{39}$ Aimone Gibson, Enrique, Para un concepto de derecho económico, cit. (n. 34), p. 27.

${ }^{40}$ Ibíd., p. 26.

${ }^{41}$ Ambos estuvieron cercanos al pensamiento cameralista. Así, por ejemplo, Ickstatt en el programa de su actividad docente en Würzburgo, distingue dos aspectos de la ciencia cameralista: un ius naturale sociale oeconomicum y ius civile oeconomicum sive camerale. El primero de éstos pertenece, como se desprende de su denominación, 
El contenido de este ius naturae sociale oeconomicum puede, según el mismo Piepenbrock, determinarse así: se trata de un derecho económico en el sentido de que se refiere a la economía del hogar. Como derecho social es un derecho aplicable a las distintas formas en las que las personas son asignadas al hogar. Como es un derecho social, sus normas se deducen de la naturaleza de la societas aeconomica que rigen ${ }^{42}$.

Finalmente Piepenbrock nos habla del derecho económico de guerra como uno de los tramos más importantes de la formación del concepto. En efecto, la primera guerra mundial, al generar, con esfuerzo, bélico, como su contrapartida una contracción del consumo, hace necesaria toda una regulación jurídica de procesos económicos que la humanidad, o desconocía, o había sencillamente olvidado. Todo este mecanismo intervencionista hace, obviamente, que el derecho dé forma a estas restricciones ${ }^{43}$.

\section{Los fundadores. Lehmann y el derecho industrial. Primera parte del} siglo $X X$.

En lo que se refiere a los fundadores del derecho económico, no se puede dejar de reconocer el "Aporte de los juristas alemanes, que desde 1908 inician serios esfuerzos doctrinales en torno a la presencia de un nuevo derecho industrial agrícola" ${ }^{44}$.

En particular, cabe recordar a Lehmann, quien en el año 1912 al dictar su clase inaugural en la Universidad de Jena, propició la creación de un derecho industrial separado y distinto del derecho mercantil.

Recordemos que el gran auge económico alemán de entonces se debía al desarrollo industrial, y en base a ello, el autor justifica un tratamiento jurídico autónomo para la industria ${ }^{45}$.

al derecho natural, que con los derechos juxtaquors ipsa natura ictiones nostras instituere nos obligat y que constituye, junto al derecho privado, una de las dos partes de la jurisprudencia. Véase. Aimone Gibson, Enrique, Para un concepto de derecho económico, cit. (n. 34), p. 27.

${ }^{42}$ Asimismo en los fisiócratas franceses, Piepenbrock ve elementos de un tratamiento del derecho económico que luego aflorará completo en la dogmática jurídica de fines del siglo XIX. Véase: Aimone Gibson, Enrique, Para un concepto de derecho económico, cit. (n. 39). p. 27.

${ }^{43}$ Aimone Gibson, Enrique, Para un concepto de derecho económico, cit. (n. 34), p. 28.

${ }^{44}$ Moore, Daniel, Derecho económico (Editorial Jurídica, Santiago de Chile, 1962), p. 20.

${ }^{45}$ El concepto general de esta nueva idea sería la empresa industrial, y en base a la preocupación sobre las siguientes materias: $i$ ) Orden de la empresa en su interior (que comprende el derecho del trabajo, el del uso del agua, de la energía y del capital); ii) Protección de la empresa hacia afuera (que se refiere al derecho represivo de 
Con esta exposición sistemática, Lehmann no deseaba ofrecer un sistema concreto de derecho industrial, sino tan sólo elaborar grandes ideas básicas, que unen los grandes problemas.

\section{Los modernos. Segunda parte del siglo XX.}

Finalmente, agregaremos a una tercera clasificación a la doctrina de los autores, y a los cuales denominaremos modernos, en tanto pensamos que es a partir de su pensamiento, que se sientan las bases de lo que actualmente entendemos por derecho económico ${ }^{46}$.

a) El continente económico de Hedemann. Justus Wilhelm Hedemann es quizá el primero de los autores alemanes que llega, con mayor precisión metodológica, al concepto de derecho económico.

Para él, el derecho económico es el ordenamiento jurídico total, en cuanto está prevalentemente fundado sobre consideraciones económicas.

De esta forma, lo que se denomine como derecho económico nacería de la posición central que la economía ocupa en el espíritu de nuestros tiempos. En otras palabras, para Hedemann el continente -que vendría siendo lo económico- se encuentra antes del contenido.

Para ello, Hedemann contrapone el derecho económico al derecho Natural, que en el siglo XVIII llevó al campo del derecho a lo que entonces constituía el centro de la visión del mundo, es decir, el amor a la naturaleza ${ }^{47}$.

En esta forma, el derecho económico aparece como un nuevo espíritu, un estilo moderno de ser del derecho, una actitud diversa a las tradicionales, que cabe descubrir en la gran mayoría de las instituciones del derecho contemporáneo.

Con esta formulación, Hedemann ocupa, en el esquema de los autores de su época, una posición única entre quienes abordan el concepto moderno del derecho económico.

En efecto, para todos los otros autores ${ }^{48}$ el derecho económico es un

la competencia desleal, el derecho de acceso al trabajo, el de intervención, de asociación, trust, etcétera), y finalmente; iii) Relaciones con la comunidad, que se refiere a los esfuerzos por eliminar los efectos desfavorables de la actividad industrial. VÉASE: Aimone Gibson, Enrique, Para un concepto de derecho económico, cit. (n. 39). p. 28.

${ }^{46}$ Según la Real Academia de la Lengua, se entiende por moderno-na (del latín modernus, "de hace poco, reciente"), a todo aquello que sea perteneciente o relativo al tiempo de quien habla o a una época reciente. Disponible en internet en www.rae.es

${ }^{47}$ Lit: Rousseau, Jean- Jacques, El contrato social (traducción de Consuelo Berges, Barcelona, Orbis, 1984); LOCKE, John, Segundo tratado sobre el gobierno civil (traducción de Carlos Mellizo, Madrid, Alianza Editorial, 1990).

${ }^{48}$ Una consideración especial merece Gustav Radbruch. Según este autor, el modo privatístico de considerar las relaciones económicas ve tan sólo en ella relacio- 
concepto selectivo que se aplica tan sólo a determinados sectores, o a determinadas normas de un ordenamiento jurídico concebido en concreto. Frente a esta idea del sector, Hedemann contrapone una época histórica dada del desenvolvimiento jurídico, y la califica como derecho económico. Así cabrá, en su pensamiento, hablar más de la época del derecho económico -que fue la suya y que entendemos sigue siendo la nuestra- más que de un sector del derecho.

Hedemann niega al concepto toda relevancia sistemática para el análisis de un derecho positivo dado, y le atribuye sólo el rol caracterizador global de un determinado tiempo jurídico.

b) Enrique R. Aftalión y el derecho social económico. Para este autor, más que derecho económico, lo que existe es un derecho social económico, el cual aparece, ante todo, como el instrumento a que recurren los legisladores para concretar en los hechos la política del intervencionismo en lo económico-social.

Es, en otros términos, la expresión jurídica de esa política. Así, el llamado derecho económico, ya caracterizado en 1935 por el jurista húngaro De Kiroly, y en 1939 por el alemán Hedemann, mediante la enumeración de sus temas fundamentales, se va perfilando con una precisión cada vez mayor, al destacarse ahora las razones últimas que establecen ciertos innegables vínculos entre instituciones jurídicas aparentemente inconexas ${ }^{49}$.

c) El derecho económico internacional, y el pensamiento de Georg Erler. Tratándose del pensamiento moderno de la doctrina

nes entre dos personas privadas que deben ser compuestas en el sentido de la justicia conmutativa. No contempla al tercero y más importante de los interesados de cada relación económica: la comunidad. Esta concepción, puramente privatística de la economía, podrá durar tan sólo mientras durara la optimista convicción del libre juego de las fuerzas y de la composición y armonización autónoma de las fuerzas y del provecho personal en dirección o en sentido no del interés personal. Este dogma -continúa RADBRUCH- se rompió al desvincularse, con la primera guerra mundial, la economía alemana de la economía mundial, y al entrar en colisión los movimientos económicos realizados ahora en el ámbito tremendamente reducido de la economía alemana. De este acontecimiento deriva, sin embargo, el derecho económico. En efecto, el derecho económico nace cuando el legislador deja de considerar y regular las relaciones económicas en el mero sentido de la justa composición de los participantes inmediatos en ellas, para hacerlo principalmente desde el punto de vista del interés económico general, de la productividad de la economía, de su economicidad. El derecho económico nace desde el momento en que el Estado deja de hacer jugar las fuerzas con criterio privatístico y decide dominar sus leyes sociológicas de acción por medio de leyes en sentido jurídico. Véase: Aimone Gibson, Enrique, Para un concepto de derecho económico, cit. (n. 34), pp. 30-31.

${ }^{49}$ Aimone Gibson, Enrique, Para un concepto de derecho económico, cit. (n. 34), p. 29. 
de los autores, el denominado derecho internacional económico no puede dejar de mencionarse.

En particular, el pensamiento de Georg Erler, quien encabezó el estudio de una serie de autores que se han referido específicamente al derecho económico internacional, sea que usen o no esta precisa denominación ${ }^{50}$. Para Erler, el derecho económico internacional tiene por objeto la regulación de la economía internacional, es decir, de la conducción de sujetos partícipes en relaciones económicas que cruzan fronteras nacionales, en cuanto estructuradas conforme o para finalidades colectivas ${ }^{51}$.

d) Cottely, y la finalidad metajurídica. Han pasado cincuenta años desde que uno de los autores de este artículo citara por primera vez la concepción del derecho económico de Esteban Cottely, y todavía seguimos creyendo que contiene quizás, una de las mejores síntesis disponibles sobre el estado actual de la investigación para encontrar un concepto de derecho económico ${ }^{52}$.

Recordemos que para este jurista argentino, el derecho económico obedece a un principium divisionis diferente, no susceptible de ser yuxtapuesto al tradicional. Dicho principium divisionis se refiere a la finalidad metajurídica o valoración de la norma.

Para estos efectos, Cottely clasifica las doctrinas existentes sobre derecho económico según su método científico, y así habla de escuelas de método formal (utilitario) y de método analítico (filosófico).

${ }^{50}$ Aimone Gibson, Enrique, Elementos para un concepto de derecho económico internacional, en Revista de Derecho de la Universidad Católica de Valparaiso, 2 (1978), p. 258.

${ }^{51} \mathrm{El}$ autor agrega que estas normas son dictadas por dos fuentes. La primera de ellas está constituida por los distintos Estados, y por los sujetos de derecho que éstos admiten o instituyen (corporaciones económicas, empresas autónomas), en especial en el campo del derecho interno, del comercio exterior del arancelario y de divisas. Está constituido también por organizaciones internacionales públicas y, en ciertos casos, por entidades privadas. Ambos grupos de normas, según Erler, están engranados íntimamente entre sí, y hoy día conforman una integración de regulación normativa de un hecho vital, material y funcionalmente indivisible. Desde un principio advierte Erler, que si el derecho económico internacional quiere o pretende regular íntegramente determinadas relaciones jurídicas internacionales, es imposible reducirlo al solo campo del derecho público. Véase: Aimone Gibson, Enrique, Elementos para un concepto de derecho económico internacional, cit. (n. 50), p. 258.

${ }^{52}$ Aimone Gibson, Enrique, Concepto y contenido del derecho público económico, cit. (n. 14), p. 141. 


\section{Examen de la evolución de los conceptos en Chile}

\section{Alcance conceptual y origen histórico ${ }^{53}$.}

Una vez analizado el origen, las ideologías y doctrinas existentes en torno al derecho económico, y antes de arribar a las reflexiones conclusivas del presente trabajo, corresponde analizar nuestra realidad local, para así tratar de acercarnos a lo que podría entenderse como nociones del derecho económico chileno.

Para ello, previamente debemos recordar un hecho histórico relevante, y esto es que el verdadero origen de lo que hoy entendemos como derecho económico, se remonta a lo que hasta fines de los años cincuenta, se denominó simplemente bajo el nombre de "política económica". En efecto, y recordando lo que uno de los autores de este artículo afirmó hace medio siglo atrás, cuando iniciábamos el estudio de esta importante rama del derecho: "Nuestras Facultades de Derecho no reaccionaron en la estructuración de estos programas ante esta evidencia, y por mucho tiempo, la cátedra de política económica era un ramo de derecho positivo, a pesar de lo que su nombre insinúa. En nuestra Facultad de la Universidad Católica de Valparaíso se suprimió la cátedra de política económica a partir de 1961, y se la reemplazó por un ramo jurídico que se denominó 'derecho público económico ${ }^{54}$, y que debía recoger, en categorías jurídicas, o bien, jurídico-económicas, todo el material jurídico que se impartía desde la cátedra de política económica" 55 .

a) Moore y el primer alcance conceptual. Fue con la obra de Daniel Moore Merino del año $1962^{56}$ que por primera vez en nuestro país se reconoce de manera expresa un concepto de derecho económico.

Efectivamente, y tal como uno de los co-autores de este artículo re-

${ }^{53}$ Para ello iniciaremos su estudio efectuando una recopilación de lo que entendemos son los seis principales alcances conceptuales acerca de lo que se ha entendido como derecho económico chileno. De esta manera, partiremos del continente para llegar al contenido, o en otras palabras, sólo arribaremos a las materias que forman parte de lo que entendemos como derecho económico chileno, a partir de su alcance conceptual.

${ }^{54}$ Una nota en justicia se debe a don Julio Ruiz Bourgeois, quien, al asumir en el año 1961 la Dirección de la Escuela de Derecho de los SS.CC. (Universidad Católica de Valparaíso), introdujo la cátedra de derecho público económico, la cual comenzó a impartirse en 1963, y que pronto se transformó en "derecho económico".

${ }_{55}$ Aimone Gibson, Enrique, Concepto y contenido del derecho público económico, cit. (n. 14), pp. 138-139.

${ }^{56}$ Moore, Daniel, Derecho económico (Editorial Jurídica, Santiago de Chile, 1962). 
conoce en su trabajo del año $1976^{57}$ "El planteamiento de Daniel Moore es también de extremo interés. Su obra es la primera escrita en Chile en que se usa la terminología de derecho económico". Se trata de un ensayo de sistematización de esta disciplina, sin entrar a realizar este desarrollo. Para él, y sin pretender una definición en su esencia de la disciplina, el derecho económico es concebido como "el conjunto de principios jurídicos que informan, y de disposiciones, generalmente de derecho público, que rigen la política económica estatal, orientada a promover un más acelerado desarrollo económico"s8.

Sin quitar valor al trabajo de Moore ${ }^{59}$, ahora, al igual que antes ${ }^{60}$, estimamos pertinente señalar con la misma convicción, que su concepto no deja de hacer nacer en nosotros una serie de observaciones ${ }^{61}$.

La primera de ellas es que el derecho económico no se concibe como una estructura simplemente normativa, sino que, además, "como el conjunto de principios jurídicos que informan" ${ }^{2}$.

57 "En concreto, el alcance conceptual de Moore intenta sistematizar y fijar el ser y el deber ser de este nuevo derecho económico, a la luz de la realidad económicojurídica nacional de la época. Para ello, califica su trabajo como un "intento modesto y sin pretensión de mayor originalidad", y coloca frente a frente al hombre ético y al hombre económico. Se apoya para estos efectos en Carnelutti, en cuanto, si hablamos de derecho económico, habremos de reconocer que debería existir un derecho no-económico. Siguiendo al insigne jurista italiano, señala que el hombre económico es el que protege y cuida sus propios intereses; en cambio, "el hombre ético vela, de preferencia, por los intereses ajenos”. Véase: AimOne GiBSON, Enrique, Para un concepto de derecho económico, cit. (n. 34), pp. 31-32.

${ }^{58}$ Moore, Daniel, Derecho económico, cit. (n. 56), p. 38, agrega: "Ahora bien, todas esas normas que tienden a encauzar la actividad económica hacia objetivos y metas de política económica, tienen una función común en la vida social y obedecen a una inspiración sustancialmente unitaria”. Véase: Aimone Gibson, Enrique, Para un concepto de derecho económico, (n. 34), pp. 31-32.

${ }^{59}$ Respecto al origen del derecho económico chileno e influencia de Daniel Moore, recientemente Yrarrázaval Covarrubias, Arturo, Orden público económico: ficción o realidad, cit. (n. 3), ha señalado que: "Posteriormente surgen los cursos de legislación económica en sus ámbitos de comercio interno y de comercio exterior y en algunas Facultades el curso de derecho financiero en forma separada del curso de derecho tributario. Así, se puede entender el concepto que Daniel Moore daba en 1962 al concebir el derecho económico como un 'conjunto de principios jurídicos que informan, y de disposiciones, generalmente de derecho público, que rigen la política económica estatal, orientada a promover un más acelerado desarrollo económico"”.

${ }^{60}$ Aimone Gibson, Enrique, Para un concepto de derecho económico, cit. (n. 34), pp. 31-32.

${ }^{61}$ Ibíd.

${ }^{62}$ Ibíd. 
La segunda observación se refiere a lo siguiente: "El derecho económico es un derecho definido por su objetivo, propender a un más acelerado desarrollo económico. A este respecto cabe expresar que el desarrollo económico hoy día ya no se concibe como una meta u objetivo socio-político estimable. En efecto, de desarrollo económico ha pasado a hablarse de desarrollo económico social, luego de penosas experiencias de políticas de desarrollo que, por descuidar las variables sociales, no consiguieron resultados positivos, para terminar ahora postulándose, como fin global de la política, sin concepto global de desarrollo, que comprendería variables de todos tipos, sociales, humanos, económicos, etc., ponderadas y unidas según determinadas prioridades, prelaciones, etc. Pues bien, si el objetivo político - "desarrollo económico"- ha desaparecido de la agenda de los políticos y de los objetivos de las políticas y de la economía normativa, ¿qué sentido tiene hablar hoy del derecho económico como el que tiende a un más acelerado desarrollo? ¿Acaso el derecho laboral, el urbanístico, el habitacional, etc., no contribuyen también a un más acelerado desarrollo? ¿Acaso el mismo derecho Civil no se ve enfrentado a un cuestionario, a un replanteo, para atender a idénticas finalidades? ¿Y son por ello derecho económico?" 63

Una tercera y última objeción que nos presenta este concepto apunta a que: "Estando de acuerdo en definir el derecho económico por la búsqueda de un valor económico, ¿por qué limitar el derecho económico al desarrollo? Supongamos un orden jurídico que pretenda estabilidad, incluso sacrificando expectativas de desarrollo, o simplemente de crecimiento, ¿podríamos suponer que en tal orden jurídico concreto no existe un derecho económico?"64.

b) Nuestro orden público económico. Luego del aporte de Moore, pasaron dos años para que uno de los autores del presente trabajo pudiera entregar su mirada en torno a lo que entendía ser y contenía este novedoso derecho público económico ${ }^{65}$.

En la oportunidad, él concluyó que lo escondido bajo el nombre de derecho público económico era posible ser atribuido y asimilado al concepto de orden público económico.

Para arribar a dicha conclusión, dicho autor distinguió tres etapas en la construcción conceptual del denominado orden público económico. Lo anterior, ya que dichas etapas todavía no resultan de suyo sumamente

\footnotetext{
${ }^{63}$ Ibíd.

${ }^{64}$ Ibíd.

${ }^{65}$ Aimone Gibson, Enrique, Concepto y contenido del derecho público económico, cit. (n. 14), pp. 149-150.
} 
valiosas para responder en nuestros días -aunque sea de manera parcial- lo que deba entenderse por derecho económico ${ }^{66}$.

La primera etapa en la construcción conceptual del orden público económico fue descrita así: "Al ser promulgado el Código Civil, tenía el Estado una función política; mas no una función económica. Nuestras ideas han cambiado. El Estado de hoy quiere dirigir la economía. Es imposible que esta concepción nueva de la economía dirigida deje intacto el contrato que había sido concebido por el liberalismo del siglo XIX"67.

Luego se señaló que: "El Estado ha impuesto un cierto orden económico que los particulares no están legitimados para derogar en sus convenciones. El orden establecido por el Estado para la producción, el cambio, la distribución de riquezas será evidentemente de naturaleza económica, pero será asimismo un orden público. Tendrá necesariamente carácter obligatorio $\mathrm{y}$, por consecuencia, serán nulas las convenciones que traten de atentar contra él. No se trata de una primacía de lo político sobre lo económico: se trata de distinguir, en las relaciones económicas entre los hombres, entre aquellas que son queridas e impuestas por el Estado y aquellas que pueden ser establecidas libremente por los particulares. Existe, pues, junto a la organización política del Estado, una organización económica tan obligatoria como la otra. Existe, en consecuencia, un orden público económico"68. Todavía se añadió: "Promoción y planificación de desarrollo económico, canalización de la inversión, gestión directa de ciertas empresas, prohibición de monopolios, preocupación por el abastecimiento de las grandes masas: he ahí algunas concreciones de tareas que se impone el Estado en lo económico con el fin de implantar un orden público económico" ${ }^{69}$.

La tercera y última etapa en esta construcción conceptual del denominado orden público económico, en tanto objeto y contenido del denominado derecho público económico, considera que el Estado se organiza bajo la fórmula de un Estado de derecho, y que: "En consecuencia, este ensanchamiento de la actividad estatal no puede significar un desmedro de los derechos fundamentales de los ciudadanos ni tampoco una brecha por donde se haga presente la dictadura y la arbitrariedad. Impuesta la necesidad de la actuación generalmente subsidiaria del Estado en estos

${ }^{66}$ Decimos "parcial", porque, tal como veremos en las conclusiones, el concepto de orden público económico nos permite explicar solo una parte de la noción de derecho económico. Véase: más abajo, p.19.

${ }^{67}$ Aimone Gibson, Enrique, Concepto y contenido del derecho público económico, cit. (n. 14), pp. 148-149.

${ }^{68}$ Ibíd.

${ }^{69}$ Véase: Aimone Gibson, Enrique, Concepto y contenido del derecho público económico, cit. (n. 14), pp. 150-151. 
aspectos del proceso económico, el orden público económico consiste en lograr la conciliación de la realización de los fines de las personas y los fines subsidiarios del Estado. Es el derecho público económico la rama del derecho que, por medio de la técnica de establecer y reconocer derechos fundamentales, de estructurar y delimitar funciones de los organismos a través de los cuales actúe el Estado, consigue esta coordinación de finalidades que hemos designado como orden público económico"70.

c) Derecho económico y el conjunto de normas jurídicas. En tercer lugar, recordaremos a Hugo Olguín, investigador del Seminario de Derecho Público de la Universidad de Chile, y quien señalaba: "Se puede definir el derecho público económico como un conjunto orgánico y sistemático de normas jurídicas de derecho Público que regulan la acción del Estado en materia económica cuando, en virtud de una política económica determinada, éste interviene directa o indirectamente sobre los fenómenos y hechos de carácter jurídico económico"71.

Olguín formó parte de aquel grupo de autores e investigadores, que precisaron la caracterización de derecho económico en un aspecto que también resultó errado a juicio de uno de los autores de este artículo. ${ }^{72}$ Lo anterior, al reconocer que este conjunto orgánico y sistemático de normas jurídicas de derecho público que regulan la acción del Estado, queda delimitado en cambio, al concepto y contenido del derecho público económico, en tanto conjunto sistemático de normas que regulan la macroeconomía ${ }^{73}$.

d) Oyarzún y una nueva toma de conciencia de lo jurídico. Fue en el año 1967cuando Rubén Oyarzún ${ }^{74}$ expresaba que el derecho económico no se encasillaría en la dicotomía derecho público/derecho privado y para lo cual afirmaba que nos encontrábamos frente a una nueva toma de conciencia de lo jurídico.

Oyarzún señaló -y coincidimos- que la fundamentación, concepto,

${ }^{70}$ Aimone Gibson, Enrique, Concepto y contenido del derecho público económico, cit. (n. 14), p. 149.

${ }^{71}$ Ibíd., p. 139.

${ }^{72}$ Véase: Aimone Gibson, Enrique, Concepto y contenido del derecho público económico, cit. (n. 14), p. 144.

${ }^{73}$ Para estos efectos, se entendió por macroeconomía al fenómeno económico, no analizado como relación entre individuos -empresario-operario, empresa-consumidor- sino vistos en su conjunto. Este conjunto tiene normas que la caracterizan y la diferencian de otras. Véase: Aimone Gibson, Enrique, Concepto y contenido del derecho público económico, cit. (n.14), p. 144.

${ }^{74}$ Oyarzún Gallegos, Rubén, El derecho económico y las nuevas orientaciones en la formación jurídica, en Revista de Derecho Económico (Seminario de Ciencias Económicas, Facultad de Ciencias Jurídicas y Sociales de la Universidad de Chile), 18 (1967), pp. 7 ss. 
y contenido del derecho económico tomaría un largo tiempo en poder desarrollarse, ya que ha de tener estrechísimas relaciones con la ciencia económica, y especialmente de las nuevas escuelas. De otro lado, el autor asimiló el ramo -y advirtió- que no se debe creer en la experiencia de la clásica rama del derecho industrial y agrícola, presente en el currículum clásico, que como cajón de sastre contenía todo aquello que no encontrase lugar en otro sitio ${ }^{75}$.

En resumen, Oyarzún reconoció la escasez de material teórico y carácter confuso del concepto de derecho económico, pero sin encontrar unidad de criterio para definir y distinguir entre lo que es un concepto y una rama del derecho.

e) La planificación económica de la sociedad según Santa María. Una década más tarde, en un trabajo titulado: Derecho económico: reflexiones sobre concepto y contenido, Raúl Santa María sostuvo: "Frente a este panorama, las Cuartas Jornadas de derecho Público, efectuadas en el mes de septiembre de 1965, en la Universidad Católica de Chile, definieron provisoriamente, a través de la Comisión de Derecho económico, esta disciplina como un: "Conjunto de principios, normas e instituciones mediante los cuales se realiza el desarrollo planificado de la sociedad en su aspectos económico"76. Para reforzar su postura, Santa María agregaba: "La visión que del derecho económico tenían las Cuartas Jornadas de Derecho Público, era en cierta medida utópica, como lo ha demostrado el tiempo en los diez años transcurridos desde entonces, y presentaba algún vacío conceptual. Ella parecía buscar un doble asidero para que una desordenada legislación pudiese encontrar su carácter de un verdadero derecho económico"'77.

f) Zavala y Morales. El contenido antes que el continente. Finalmente, traemos a colación lo que José Luis Zavala y Joaquín Morales entendieron en torno a la noción de derecho económico ${ }^{78}$. Para ellos: "Como todo concepto, él se construye a base de su contenido, por lo que desde hace décadas la doctrina se ha preguntado qué tópicos aborda el derecho económico para poder dar una definición de él"79.

Esta última afirmación nos parece sumamente discutible, porque,

${ }^{75}$ Ibíd.

${ }^{76}$ Santa María, Raúl, Derecho económico, cit. (n. 2), p. 295.

${ }^{77}$ Santa María, Raúl, Derecho económico, cit. (n. 2), pp. 295-299.

${ }^{78}$ Zavala Ortiz, José Luis - Morales Godoy, Joaquín, Derecho económico (2aa edición, LexisNexis, Santiago, 2014), p. 8

${ }^{79}$ Ibíd., p. 8. 
al menos para nosotros, la relación es completamente inversa, en tanto precisamente es el concepto el que determina el contenido y no al revés ${ }^{80}$.

\section{Criterios para considerar al derecho económico como rama de la ciencia} jurídica chilena.

Antes de referirnos a las reflexiones finales del presente trabajo, quisiéramos hacer una pequeña mención en torno al lugar que entendemos, le corresponde al derecho económico en tanto rama de la ciencia jurídica chilena ${ }^{81}$.

Para dichos efectos, reconoceremos tres criterios. Los dos primeros fueron descritos por uno de los autores del presente artículo con ocasión del trabajo titulado: Concepto y contenido del derecho público económico en $1964^{82}$, mientras que el tercer y último criterio, lo esbozó más tarde en el año $1978^{83}$.

En primer lugar, se puede intentar una definición inquiriendo la finalidad de la norma. En este primer escenario: "El derecho público económico es aquella rama que tiende a establecer el orden público económico" ${ }^{84}$.

En segundo lugar, podemos intentar una definición examinando el resultado de la norma o de la institución creada. Con este segundo criterio: "El derecho público económico sería la rama que organiza el sistema y la estructura institucional económicos" ${ }^{85}$. De esta forma, se concluye: "El derecho público económico será una rama del derecho con-

${ }^{80}$ Para Zavala y Morales el contenido sería fundamentalmente el siguiente: Mercado de capitales; Banco Central; Operaciones de cambio o internacionales; Protección de la libre competencia; Protección del consumidor, e Inversión extranjera. Véase: Zavala Ortiz, José Luis - Morales Godoy, Joaquín, Derecho económico, cit. (n. 78).

${ }^{81}$ Véase, más arriba,. II, 3.

${ }^{82}$ Aimone Gibson, Enrique, Concepto y contenido del derecho público económico, cit. (n. 14), p. 145.

${ }^{83}$ Aimone Gibson, Enrique, Elementos para un concepto de derecho económico internacional, cit. (n.50), pp. 262-264.

${ }^{84}$ Aimone Gibson, Enrique, Concepto y contenido del derecho público económico, cit. (n. 14), p. 149.

${ }^{85}$ En lo que guarda relación con el derecho económico en tanto rama de la ciencia jurídica, CRISÓlogo-Bustos - citado por SANTA María- indica que: "Establecido el plan en las condiciones antes dichas el derecho económico encontrará las condiciones óptimas para alcanzar la categoría de una rama autónoma dentro de las Ciencias Jurídicas: instituciones, reglamentación orgánica y jurisdicción”, agregando que mientras ello no ocurra, "no cabe hablar de la existencia de un Derecho económico, sino tan sólo de una Legislación Económica”. Véase: SANTA María, Raúl, Derecho económico, cit. (n. 2), pp. 295-299. 
cebida en un sentido diferente al tradicional. Así, en un sentido figurado podemos decir que los ramos tradicionales de la ciencia del derecho cortan la materia jurídica en un sentido horizontal, mientras que el derecho público económico lo hace en un sentido vertical. Por ello, el derecho público económico contiene materias que también pertenecen a otras ramas del derecho. Nuestra disciplina no hace otra cosa que reunir en un sentido coherente y armónico todas las normas legales que tienden a realizar el orden público económico o que forman y constituyen la estructura económica institucional. Así, podemos ver cómo hay materias de nuestra disciplina que también lo son de otras: derecho de propiedad sobre los factores de producción (derecho civil); delito económico (derecho penal); estructura de reparticiones públicas con atribuciones económicas como Corporación de Fomento de la Producción (derecho administrativo)" ${ }^{86}$. Y con respecto al contenido de este derecho público económico, se pudo añadir: "El criterio, en consecuencia, para determinar si una norma es o no integrante del derecho público económico es inquirir si ella estructura o no la macroeconomía, o, dicho de otro modo, si tiende o no a realizar un orden público económico" 87 .

El tercer y último criterio, para determinar si nos encontramos frente a una u otra rama del derecho, lo recogemos a partir de una importante conclusión a la cual uno de los autores del presente trabajo arribó en 1978 al tratar los elementos del concepto de derecho económico internacional, y más particularmente al analizar la relación existente entre el con tenido y los límites del derecho económico internacional. En la ocasión, señaló: "Una rama del derecho no sólo queda fijada por su concepto, contenido en una definición, sino también por la determinación lo más precisa posible, de los límites con otras disciplinas jurídicas o ramas del derecho" ${ }^{88}$.

\section{INDIVIDUALIDAD DEL DERECHO ECONÓMICO}

\section{Planteamiento metodológico.}

Una vez arribados a este punto del presente trabajo, debemos resolver si es o no posible reconocer la existencia de una rama y asignatura del derecho a la cual podamos denominar bajo el nombre de derecho económico.

Ante dicha inquietud, afloran las alternativas de integrar el derecho económico, o bien, de excluirlo.

\footnotetext{
${ }^{86}$ Aimone Gibson, Enrique, Concepto y contenido del derecho público económico, cit. (n. 14), p. 152.

${ }^{87}$ Ibíd., p. 152.

${ }^{88}$ Aimone Gibson, Enrique, Elementos para un concepto de derecho económico internacional, cit. (n.50), p. 262.
} 
Si optamos por el primer camino, es decir, logramos integrar y reconocer la existencia de este derecho económico, deberemos entonces abocarnos a examinar el contenido de dicho continente, y ante lo cual, tendremos necesariamente que examinar la influencia de lo económico en la ciencia jurídica, y en consecuencia deberemos pasar revista entre otras materias, al rol del Estado en la economía, al marco normativo del mercado y/o de las actividades económicas reguladas.

Si en cambio prescindimos de él, ello no quiere decir que tales materias queden sin examen, ya que se insertarán necesariamente en otras áreas del derecho, con las cuales no formará necesariamente un sistema, por lo que su comprensión y coherencia se debilitará inevitablemente ${ }^{89}$.

Así las cosas, nuestra postura es la de reconocer no sólo la existencia, sino que además la autonomía del derecho económico, y desde ahí, señalar con precisión, en qué consiste, o en otras palabras, qué entendemos por derecho económico.

En nuestra opinión, el derecho económico presenta una doble dimensión y una característica particular.

La primera dimensión del derecho económico es aquella que considera la influencia de la ciencia económica en la ciencia jurídica, o si se quiere decir en otras palabras, partir de lo económico para llegar a lo jurídico, ya sea en un plano local, o bien, internacional.

Un segundo estado de la cuestión, considera al derecho económico desde la mirada del tipo de instrumento o norma legal que lo ampara, ya sea de rango constitucional u otra inferior.

Finalmente, encontramos una característica particular del derecho económico, cual es su autonomía, en tanto rama de la ciencia jurídica distinta y diferenciada de las demás.

2. La doble influencia económica en el derecho. "De lo económico a lo jurídico".

a) El derecho económico nacional. Tal como señalamos, la primera dimensión que permite explicar qué debemos entender por derecho económico, es decir, aquella que considera la influencia de los principios y postulados de la ciencia económica en el derecho.

En otras palabras, este primer nivel nos lleva a considerar la influencia de lo económico hacia lo jurídico, y no al revés como suele ocurrir.

${ }^{89}$ Respecto a la relación entre derecho y economía, sugerimos ver: GUERRERO BeCAR, José Luis, Derecho y economía, una relación necesaria. Algunas aproximaciones en la constitución económica chilena, en Revista de la Facultad de Derecho, 27 (Universidad Francisco Marroquín, 2009), pp. 48-63. 
Bajo esta mirada, la influencia de lo económico en lo jurídico alcanza una doble perspectiva, según se trate del plano local o bien internacional.

En el primer caso, hablaremos de orden público económico, y en el segundo de derecho económico internacional.

Para estos efectos, entendernos que lo económico es aquello que presenta un doble carácter, a saber, ser útil y escaso.

Esta doble consideración, resulta más inclusiva que aquella que convocó hace cincuenta años atrás a uno de los autores del presente trabajo ${ }^{90}$, cuando la globalización todavía se encontraba en plena etapa de su desarrollo. En la ocasión, se concluyó que el denominado derecho público económico era, se explicaba, e incluso se contenía bajo el concepto de orden público económico ${ }^{91}$.

Hoy, en cambio, los autores reconocemos con claridad la existencia de un derecho público y también un derecho privado, en y hacia el derecho económico.

Por la misma razón, ahora nos resulta insuficiente aquella mirada que frente a la pregunta: ¿A qué tienden estas normas macroeconómicas?, señalaba que no era otra cosa que a establecer el orden público económico. A propósito, Santa María, citando un trabajo de Aimone del año 1964, señalaba: "Despojado el derecho económico de su gran objetivo y de la cohesión del plan, sólo podría existir un derecho empírico, cuyo único valor radicaría en su mayor o menor utilidad para servir objetivos circunstanciales de la política económica" y posteriormente, agrega: "No obstante, otros autores como Enrique Aimone esbozan para el derecho económico un alcance conceptual bastante amplio, como rama que tiende a establecer el orden público económico"’2. En la misma línea Oscar Aramayo expresa: "Piensa que el derecho económico tiende a preservar el orden público económico, reconociendo que éste es cambiante y dinámico y que se vincula a la ejecución de la política económica del Estado a través de la programación del desarrollo"; pero agrega: "Estamos lejos de adherir a una teoría que anule la norma como juicio de valor y entendemos, por

${ }^{90}$ Aimone Gibson, Enrique, Concepto y contenido del derecho público económico, cit. (n. 14), pp. 149-152.

${ }^{91}$ Yrarrázaval Covarrubias, Arturo, Orden público económico: ficción o realidad, cit. (n.3), recuerda que: "El orden público económico aparece definido por nuestra jurisprudencia en 1954 como "el conjunto de medidas y reglas legales que dirigen la economía, organizando la producción y distribución de las riquezas en armonía con los intereses de la sociedad. De esta noción ha surgido el concepto de delito económico que viene a ser, precisamente, todo hecho que importe una transgresión a aquel orden económico".

${ }^{92}$ Santa María, Raúl, Derecho económico, cit. (n. 2), pp. 295-299. 
el contrario, que deben realizarse todos los esfuerzos que sean necesarios para que la sociedad encauce su vida de relación sobre la base de normas estables, que interpreten el sentido de justicia y equilibrio que debe presidir las relaciones humanas" ${ }^{\prime 3}$.

b) El derecho económico internacional. Como indicamos, la influencia de lo económico en lo jurídico también reconoce un nivel internacional, bajo el denominado derecho económico internacional.

Así lo vio uno de los autores del presente trabajo, cuando en los albores de la década de los ochenta señalaba: "Si entendemos por derecho económico internacional un derecho que regula relaciones internacionales, mal podemos considerar ambos términos como equivalentes. El derecho económico internacional se hace presente cuando hay relaciones internacionales económicas reguladas por el derecho" ${ }^{4}$. No obstante lo anterior, no podemos dejar de recordar que así como reconocimos la influencia de lo económico en la ciencia jurídica internacional, de la misma forma: "A juicio nuestro, todo este derecho comercial internacional (lex mercatoria) está contenido en el derecho económico internacional si persistimos en definir este último como la regulación jurídica de la vida económica internacional. Las reflexiones que anteceden son significativas no sólo porque tocan los puntos más conflictivos de asignación de normas a una u otra categoría de normas, sino también porque abren una luz acerca del contenido esencial del derecho económico internacional. Creemos que el contenido esencial de esta rama son, precisamente, todas las normas de este derecho comercial internacional, como asimismo las normas de contenido económico del derecho internacional. Coincidimos con Erler en que ambos cuerpos de normas rigen solidariamente, conformando una unidad cada vez más interconectada, esta vasta realidad que llamamos las relaciones económicas internacionales" ${ }^{95}$.

\section{Derecho económico constitucional, derecho económico legal y derecho} económico reglamentario.

Un segundo intento por tratar de responder a la pregunta ¿qué entendemos por derecho económico?, considera el tipo y rango de norma utilizada para plasmar la influencia de lo económico en la ciencia del derecho.

${ }^{93}$ Aramayo, Oscar, El orden público económico, en Boletín del Centro de Investigaciones de Derecho Económico de la Universidad Católica de Chile, 1 (1967), p. 7. Véase Aramayo, Oscar, Legislación económica (Editorial Jurídica, Santiago de Chile, 1958), II. pp. 2-5.

${ }^{94}$ Aimone Gibson, Enrique, Elementos para un concepto de derecho económico internacional, cit. (n. 50), p. 262.

${ }^{95}$ Ibíd., p. 264. 
De esta forma, reconocemos un derecho económico constitucional, un derecho económico legal y finalmente un derecho económico reglamentario, según si la influencia se ve plasmada a nivel de norma de rango constitucional, legal, o reglamentaria.

A nivel constitucional, reconocemos la existencia de una serie de normas constitucionales de contenido económico, agrupadas bajo lo que la doctrina denomina como constitución económica ${ }^{96}$.

Por su parte, a nivel legal es en donde se reconocen las más diversas actividades económicas, reguladas en cada caso por una ley específica (p. ej. energía, banca, telecomunicaciones, transporte).

Asimismo incluiremos en este nivel a otras subáreas del derecho económico, entre las cuales cabe destacar al derecho de la competencia, al derecho del consumo ${ }^{97} \mathrm{y}$ otros ${ }^{98}$.

Finalmente, en lo que denominaremos como derecho económico

${ }^{96}$ Véase, más arriba, III,2.

${ }^{97}$ Cabe señalar que el derecho del consumidor no ha sido incorporado ex profeso, en tanto entendemos que su pertenencia al derecho económico no es exclusiva, al compartir en su propia naturaleza, algunos rasgos sustantivos del derecho civil y adjetivos del derecho procesal.

${ }^{98}$ En lo que entiende como el contenido del derecho económico, YrarrázaVAL Covarrubias, Arturo, Orden público económico: ficción o realidad, cit. (n. 3), señala: "He querido demostrar a través de este somero listado que el derecho económico tiene hoy en día un contenido propio que por lo profuso que es, puede ser analizado en grandes líneas en los estudios de derecho y que ya empieza a profundizarse a través de programas de derecho de la empresa", y luego agrega: "Las leyes de defensa de la libre competencia y de protección al consumidor son de gran importancia en las relaciones comerciales diarias y en la defensa del bien jurídico de la competencia. La ley del Banco Central con su desarrollo institucional y de las funciones monetarias, crediticias y cambiarias, tienen un contenido económico de singular relevancia macroeconómica y de impacto sobre el ahorro y la inversión. El Consejo del Banco Central a través de sus acuerdos está permanentemente normando estas materias, el contenido de los Compendios de Normas Financieras y de Cambios internacionales, Exportaciones e Importaciones impresionan por lo profuso y cambiante. La Ley General de Bancos y la de la Superintendencia de Bancos e Instituciones Financieras, conjuntamente con la normativa proveniente de la Superintendencia, constituye una amplia área de análisis económico. En materia de valores, la ley y la Superintendencia de Valores y Seguros aportan otro tanto. En las relaciones económicas internacionales hay que destacar la normativa sobre la inversión extranjera, fondos de inversión, anti subvenciones y dumping, acuerdos y tratados de libre comercio y la normativa cambiaria existente en nuestro país desde 1932. El actuar del Estado en su quehacer económico se analiza en la ley de Administración Financiera del Estado, Ley de Presupuesto y legislación de planificación. Por último nos encontramos con la legislación de incentivos ya sean regionales o por actividad económica. No he incluido en este listado fundamental la normativa económica en materia de seguridad social, 
reglamentario, comprenderemos a esa enorme masa normativa que se estructura a partir del ejercicio de la potestad reglamentaria por parte de la administración del Estado, en todos aquellos ámbitos relacionados directa o indirectamente con lo económico.

\section{La caracteristica del derecho económico. Su autonomía.}

$\mathrm{Al}$ iniciar este estudio, nos referimos someramente a las relaciones existentes entre el derecho económico y otras ramas de la ciencia jurídica ${ }^{99}$.

Ahora, en el cierre, una vez establecidas las dos dimensiones que en nuestra opinión permiten comprender en qué consiste esta rama del derecho, corresponde añadirle una característica, esto es, su autonomía ${ }^{100}$.

Por la misma razón, compartimos plenamente el juicio de Yrarrázaval Covarrubias, cuando señala: "El derecho económico no es derecho administrativo ni derecho comercial, es autónomo. La evolución que ha tenido el derecho económico especialmente en los últimos 25 años en Chile permite diferenciarlo claramente". Y agrega: "Difícil habría sido plantearse el tema del contenido fundamental del derecho económico hace algunas décadas. Prueba de ello fue la inexistencia del ramo dentro de los estudios de derecho. Sin embargo, hoy en día se puede constatar en Chile y en todos los regímenes jurídicos desarrollados, un contenido bastante claro y específico. En primer lugar nos encontramos con una constitución que contiene a mi juicio todos los principios económicos fundamentales. En el plano de la ley, la legislación económica es hoy en día profusa y abarca variados campos" ${ }^{\prime 101}$.

\section{Al cierre, dos reflexiones conclusivas.}

Como corolario, efectuaremos una reflexión conclusiva acerca de dos temas que a la fecha de hoy todavía cuentan con un incipiente tratamiento doctrinario, como lo son, por una parte, la noción de lo que entendemos como derecho (económico) regulatorio, y por otra, la determinación más precisa del contenido del derecho económico.

a) Actividades económicas reguladas. Base del derecho

salud, laboral y de sociedades anónimas y bursátiles. Asimismo, hoy en día nadie duda de la íntima relación con el derecho financiero y tributario".

${ }^{99}$ Véase los capítulos I y II.

${ }^{100} \mathrm{Si}$ bien es cierto que dicha característica no es ni exclusiva ni tampoco excluyente del derecho económico (ya que también la poseen otras disciplinas de la ciencia jurídica), entendemos que sí permite dotarla de una necesaria consistencia, en lo que a dogmática jurídica se refiere.

${ }^{101}$ Véase: Yrarrázaval Covarrubias, Arturo, Orden público económico: ficción o realidad, cit. (n. 3). 
económico regulatorio. En primer término, nos referiremos someramente al derecho regulatorio o más precisamente, al derecho económico regulatorio.

Sin perjuicio del estudio que podamos efectuar en fututos trabajos sobre esta materia, por ahora, nos limitaremos a señalar que el denominado derecho regulatorio no es más que una limitación de la libertad a través o por medio de una norma.

En un primer estadio, dicha norma regula o limita aquella libertad anterior, que a vía de derecho natural, existe para todos quienes participen directa o indirectamente como agentes del mercado, sea que pertenezcan a la esfera pública o privada.

Luego, tras esa limitación, corresponde preguntarse si todas las actividades admiten y merecen la referida regulación. Ahí es donde surge lo que algunos simplemente denominan como derecho regulatorio, y que nosotros entendemos como "actividades económicas reguladas", según se da cuenta y explica en detalle la reciente obra de uno de los autores del presente artículo ${ }^{102}$.

Sin entrar en una exposición detallada de ella nos limitaremos a recordar dos de sus principales ideas, y en base a las cuales es y sigue siendo lo económico aquello que en definitiva permite explicar de manera coherente porqué razón en sólo algunas y no todas las actividades económicas, lo que da sentido a lo que entendemos constituye el derecho económico regulatorio.

La primera idea coincide con lo expresado por William K. Jones ${ }^{103}$, y consiste en que para describir una clase de actividades económicas como "reguladas", implica que haya otras que son "no reguladas"104.

De otro lado: "Para que una actividad económica sea clasificada como regulada en el específico sentido aquí empleado, debe quedar sometida a un control de gobierno que: $i$ ) Sea distinto del control que se aplica a la generalidad de la actividad económica; ii) Esté preocupada de amplios objetivos económicos; iii) Se aplique directamente a la conducta en la

${ }^{102}$ Aimone Gibson, Enrique, Actividades económicas reguladas. Teoría y casos (Santiago, Thomson Reuters, 2014).

${ }^{103}$ JONES, William, Regulated Industries. Cases and Materials (Brooklyn, University of Columbia, 1967). Cfr. Aimone Gibson, Enrique, Actividades económicas reguladas, cit. (n. 102), p. 3.

${ }^{104}$ En la misma línea de ideas, AimOne Gibson, Enrique, Actividades económicas reguladas, cit. (n. 102), p. 4 afirma que: "Nuestro intento es el de fundamentar y explicar por qué a determinadas ramas de industria y comercio llamamos "reguladas" siguiendo a Jones, por estar sometidas a una normativa jurídica específica, compleja y adecuada a su naturaleza, sin que se prescinda de la generalmente aplicable (tributaria, laboral, ambiental)". 
industria; y iv) Se aplique por mecanismos gubernamentales relativamente formalizados" ${ }^{105}$.

b) El contenido del derecho económico. Una segunda y final reflexión conclusiva apunta a la determinación más precisa del contenido del derecho económico. Esto se refiere a la búsqueda del aquel ansiado contenido para todo aquel continente que -entendemos- ya ha podido ser debidamente delimitado. Para ello no cabe más que reconocer y compartir nuevamente la inquietud que hacia inicios de los años sesenta nos entregaba Esteban Cottely en el sentido que "es más fácil crear el nuevo concepto que delimitar su contenido" ${ }^{106}$.

En esa misma línea de ideas, coincidimos una vez más, con Yrarrázaval Covarrubias, en orden a que: "El contenido del derecho económico ya está lo suficientemente decantado. Corresponde ahora hacer análisis jurídicos más profundos basándose especialmente en nuestra evolución y en el derecho comparado. Llamo la atención que, a pesar de reconocer la trascendencia del derecho comparado, es a mi juicio fundamental elegir bien el derecho y la legislación económica más apropiada y adecuada para nuestra realidad chilena" ${ }^{107}$.

Una vez resuelta aquella interrogante, recién se nos abre el espacio para una futura determinación de aquella parte de la ciencia económica que de manera precisa si requiere ser objeto de protección o en su caso de regulación por parte de la norma jurídica.

Por lo mismo, creemos que el siglo XXI nos presenta un derecho económico maduro, bien definido en lo conceptual, y en donde lo económico juega un rol fundamental para la determinación de aquel estado previo de la cuestión como lo es su alcance conceptual.

\section{BibLIOGRÁFíA}

Aimone Gibson, Enrique, Actividades económicas reguladas. Teoría y casos (Valparaíso, Thomson Reuters, 2014).

Aimone Gibson, Enrique, Concepto y contenido del derecho público económico, en Revista de Derecho y Ciencias Sociales, Facultad de Ciencias Jurídicas y Sociales y Colegio de Abogados de Concepción, 128 (1964).

Aimone Gibson, Enrique, Derecho económico internacional (Valparaíso, Ediciones Universitarias de Valparaíso, 1980).

Aimone Gibson, Enrique, Elementos para un concepto de derecho económico internacional, en Revista de Derecho, de la Universidad Católica de Valparaiso, 2 (1978).

${ }^{105}$ Ibíd., p. 4.

${ }^{106}$ Cottely, Esteban, Derecho económico, cit. (n. 1), p. 25.

${ }^{107}$ Véase: YrarrázaVal Covarrubias, Arturo, Orden público económico: ficción o realidad, cit. (n.3). 
Aimone Gibson, Enrique, Para un concepto de derecho económico, en Revista de Derecho, 164 (Universidad de Concepción, 1976).

Aramayo, Oscar, Legislación Económica (Editorial Jurídica, Santiago de Chile, 1958), II.

Aramayo, Oscar, El Orden Público Económico, en Boletín del Centro de Investigaciones de Derecho Económico de la Universidad Católica de Chile, 1(1967).

BASCUÑÁN VALDÉS, Aníbal, Introducción al estudio de las ciencias jurídicas y sociales (2a edición, Santiago, Editorial Jurídica de Chile, 1960).

Cabrillac, Rémy, Las codificaciones (traducción de Paulina Pulido Velasco y Claudia Bulnes Olivares, Santiago, Flandes Indiano, 2009).

Carbonnier, Jean, Droit civil, IV: Les obligations (Paris, Presses Universitaires de France, 1956).

Constantinesco, Leontin-Jean, Traité de Droit Comparé (Paris, 1972).

Coтtely, Esteban, Derecho económico, en Trimestre Económico, 28 (México, Fondo Cultura Económica, 1961) 109.

FARJAT, Gerard, L'ordre public économique (Paris, Librairie Général de Droit et Jurisprudence, 1963).

Fermandois VöHringer, Arturo, Ripert y su influencia en el concepto de orden público económico: auge y caída de una visión dirigista, en Revista Chilena de Derecho, 32 (2005).

Glendon, Mary Ann - Gordon, Michael W - Carozza, Paolo G, Comparative Legal Traditions (2a edición, St. Paul, Minn., West Group, 1999).

Guerrero Becar, José Luis, Derecho y economía, una relación necesaria. Algunas aproximaciones en la constitución económica chilena, en Revista de la Facultad de Derecho, 27 (Universidad Francisco Marroquín, 2009).

Guerrero BeCAR, José Luis, La libertad para desarrollar actividades económicas del art. $19 N^{o} 21$ y la constitución económica; en Persona y Sociedad, 3 (Instituto Latinoamericano de Ciencias Sociales - Universidad Alberto Hurtado 2000) 4.

Guerrero BeCAr, José Luis, Regulación constitucional del orden económico. La experiencia chilena: Constitución Politica de la República de 1980 (memoria de prueba, Universidad Católica de Valparaíso, 1991.

GuZMán BRITo, Alejandro, Andrés Bello codificador. Historia de la fijación y codificación del derecho civil en Chile (Santiago, Ediciones de la Universidad de Chile, 1982), I.

GuZMÁn Brito, Alejandro, La codificación civil en Iberoamérica. Siglos XIX y XX (Santiago, Editorial Jurídica de Chile, 2000).

GuZMÁN BRITO, Alejandro, La influencia del Código Civil francés en las codificaciones americanas, en Cuadernos de análisis jurídicos: De la codificación a la descodificación (Santiago, Ediciones Universidad Diego Portales, Escuela de Derecho, 2005) II.

GuZmán Brito, Alejandro, Para la historia de la fijación del derecho civil en Chile durante la República, VIII: Crítica al derecho vigente como presupuesto de la codificación en torno al primer tercio del siglo XIX, en Revista de Estudios Histórico-Jurídicos, 5 (Valparaíso, 1980).

Jones, William, Regulated Industries. Cases and Materials (Brooklyn, University of Columbia 1967).

LOCKE, John, Segundo tratado sobre el gobierno civil (traducción de Carlos Mellizo, Madrid, Alianza Editorial, 1990).

Moore, Daniel; Derecho económico (Santiago, Editorial Jurídica de Chile, 1962).

Oyarzún Gallegos, Rubén, El derecho económico y las nuevas orientaciones en la 
formación jurídica, en Revista de Derecho Económico, 18 (Facultad de Ciencias Jurídicas y Sociales, Universidad de Chile, 1967).

RADBRUCH, Gustav, Introducción a la jurisprudencia (Stuttgart, 1964).

RIPERT, Georges, Le regime democratique et le droit civil moderne (Paris, Librairie Général de Droit et Jurisprudence, 1936).

Rousseau, Jean-Jacques, El contrato social (traducción de Consuelo Berges, Barcelona, Orbis, 1984).

San Agustín, Obras de San Agustín en edición bilingüe (Madrid, Biblioteca de Autores Cristianos, 1969).

SAnTa María, Raúl, Derecho económico: reflexiones sobre concepto y contenido; en Revista Chilena de Derecho, 4 (1977).

Tiedemann, Klaus, El concepto de derecho económico, de derecho penal económico y de delito económico, en Revista Chilena de Derecho 10 (1983).

Turner SAelzer, Susan, Reseñas de "Las codificaciones" de Remy Cabrillac, en Revista de Derecho de la Universidad Austral, 22 (Valdivia, 2009) 1.

Yrarrázaval Covarrubias, Arturo, Orden público económico: ficción o realidad, en Revista del Abogado, 15 (1999), disponible en internet http://www.colegioabogados.cl

Zavala Ortiz, José Luis - Morales Godoy, Joaquín, Derecho económico (2a edición, Santiago, LexisNexis, 2014). 